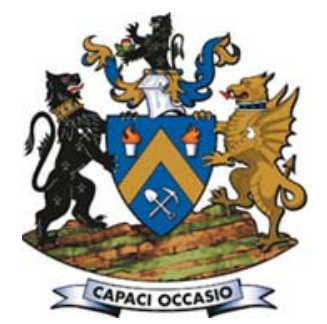

\title{
Optimization of flotation pH for the reverse flotation of an African low- grade BIF haematite ore
}

\author{
by A. Fouchee*, N. Naudé* ${ }^{*}$ S. Naik ${ }^{\dagger}$, and K. Schommarz*
}

\section{Synopsis}

This article presents laboratory test work conducted on an African haematite ore to determine the influence of the flotation pulp $\mathrm{pH}$ on the final iron grade and recovery. Results show that a combination of an isodecyl ether propylene amine/amino acetate and 1,3-propanediamine, $\mathrm{N}$-(3-(C10-C16-alkyloxy) propyl)-derivatives collector is suitable for separating haematite from quartz. Higher iron grades were obtained at $\mathrm{pH}$ levels between neutral and $\mathrm{pH}$ 9. This underlines the importance of the surface charge effect of the ore on its flotation characteristics. The results serve as good baseline conditions for further optimization.

Keywords

iron ore, froth flotation, mineral processing, flotation reagents.

\section{Introduction}

Beneficiation of iron ore by flotation is widely used in Brazil, India and China. In Africa, however, this practice is not yet commercially developed.

The aim of this test work is to serve as a starting point by establishing suitable $\mathrm{pH}$ conditions for the development of a practically implementable reagent suite, which will then be included in a larger beneficiation circuit for producing high-grade iron ore sinter feed.

In the literature, African iron ore types are graded as low-grade $(60.0-62.9 \% \mathrm{Fe} ; 8.6-$ $12.5 \% \mathrm{SiO}_{2}$ and insolubles), high-grade (66.0$69.9 \% \mathrm{Fe} ; 0.8-4.5 \% \mathrm{SiO}_{2}$ and insolubles), and meduim-grade as the remaining portion (Astrup et al., 1998). The low-grade ore used in this work contains less than $60 \% \mathrm{Fe}$.

For Brazilian ores consisting of a combination of haematite and quartz, it is common to use corn starch as a depressant and ether amine blends as collectors with additional frothing characteristic (Araujo et al., 2005). Work by Turrer and Peres (2010) shows the possibility of using other depressants successfully as well.

The main mechanism of the reverse flotation of quartz from iron ore is based on the electrostatic theory of flotation. This is due to the strong $\mathrm{pH}$ dependence of the zeta potential of the mineral edge planes on silicate particles (Fuerstenau and Pradip. 2005).
An electrical double layer, (inner and outer Helmotz planes), as illustrated in Figure 1, forms on the surface of particles submerged in a solution. The charge in the outer Helmotz plane is depicted by the potential-determining ions on the mineral surface. The ion type that is predominantly concentrated on the surface is determined by the solution $\mathrm{pH}$.

In general, a higher quartz recovery to the froth phase is attained at $\mathrm{pH} \mathrm{9,} \mathrm{which} \mathrm{is}$ attributed mainly to the largest negative surface charge at this pH, (Vieira and Peres, 2007), as indicated in Figure 2.

Hydrophobicity of quartz increases as the zeta potential becomes more negative, due to the increased force between the negatively charged quartz surface and the positively charged amine molecule.

Sirkeci (2000) attributed the increased quantities of silicate minerals reporting to the froth phase to the equilibrium between ionized and molecular amine species at $\mathrm{pH}$ 9.3.

\section{Materials and methods}

A low-grade haematite ore from Africa was utilized for this flotation test work. Ore characterization consisted of particle size distribution, mineralogical characterization, and compositional characterization. Sample splitting and blending at a representative level were conducted to produce feed samples for laboratory-scale flotation tests.

The flotation reagent suite included $150 \mathrm{~g} / \mathrm{t}$ combined isodecyl ether propylene amine/amino acetate and 1,3-P-propanediamine, N-(3-(C10-C16-alkyloxy) propyl)derivatives collector and a causticized corn starch, with solution concentration of $2.0 \%$ by

* Department of Materials Science and Metallurgical Engineering, University of Pretoria, Pretoria, South Africa.

+ Anglo American Technical Solutions.

(c) The Southern African Institute of Mining and Metallurgy, 2016. ISSN 2225-6253. Paper received May 2015; revised paper received Nov. 2015. 


\section{Optimization of flotation pH for the flotation of a low grade haematite ore}

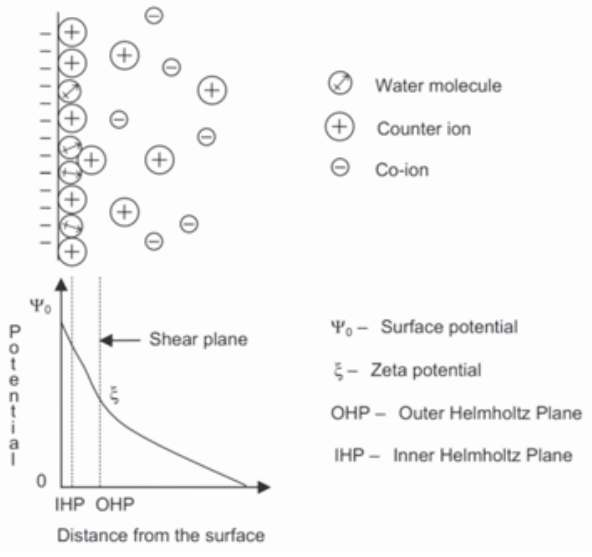

Figure 1-Schematic representation of the electrical double layer theory of mineral surface charge (Alvarez-Silva et al. 2010)

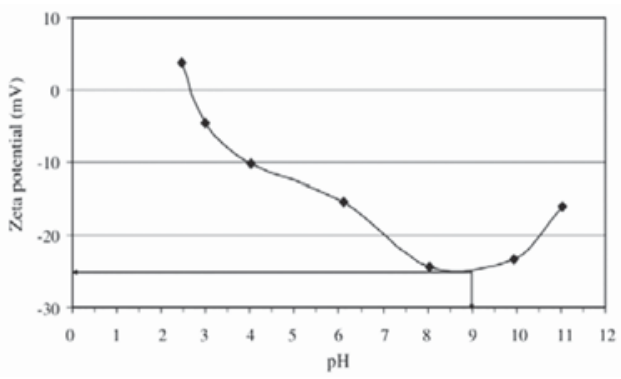

Figure 2-Zeta potential of quartz as a function of pH (Vieira and Peres, 2007)

weight. An impeller speed of $800 \mathrm{r} / \mathrm{min}$ was maintained for conditioning (at $66 \%$ solids by weight) and flotation (at 30\% solids by weight). The flotation medium consisted of synthesized process water.

The flotation pulp $\mathrm{pH}$ was adjusted by addition of chemical-grade $\mathrm{NaOH}$ or $\mathrm{H}_{2} \mathrm{SO}_{4}$. Chemical-grade corn starch and dextrin depressants were evaluated, as well as industrialgrade sodium silicate dispersants.

Each feed sample was milled to approximately $80 \%$ passing $30 \mu \mathrm{m}$ in a laboratory-scale mill, with hardened steel rods as grinding media.

Flotation tests were conducted in a Denver-D12 laboratory flotation machine and a 2.6 litre vessel.

Chemical analysis of $\mathrm{Fe}$ and $\mathrm{SiO}_{2}$ was carried out using Xray fluorescence. Mineralogical characterization was performed with by X-ray diffraction.

\section{Results and discussion}

The results are presented in terms of a silica rougher flotation circuit. The reverse flotation of iron ore is aimed at increasing the iron content in the silica rougher tails to a saleable product grade.

\section{Ore characterization}

Seven samples of iron ore with a banded iron formation (BIF) structure were blended and characterized as a composite. Mineralogical analysis by XRD indicated only the presence of haematite and quartz in the ore. The relative phase amounts, calculated by the Rietveld method (Bergmann and Kleeberg, 1998), amounted to $47.5 \%$ haematite and $52.5 \%$ quartz.

XRF analysis, however, indicated $47.6 \% \mathrm{Fe}_{2} \mathrm{O}_{3}$ and $51.4 \% \mathrm{SiO}_{2}$. The balance of less than $1.0 \%$ (by weight) consisted predominantly of $\mathrm{Al}_{2} \mathrm{O}_{3}$ and $\mathrm{K}_{2} \mathrm{O}$. This indicated the possibility for minor amounts of additional gangue minerals in the feed.

Grinding curves, shown in Figure 3, were constructed for 10-40 minutes' grinding times. Interpolation of the 20minute and 30-minute grinding data shows that milling of each sample for approximately 25 minutes would result in the desired feed particle size range of at least $80 \%$ passing $30 \mu \mathrm{m}$.

\section{Reagent selectivity}

The starting point of this test work was to determine a suitable depressant. The iron grade and iron recovery from a laboratory flotation test at each of the individual pH levels with different depressants is shown in Figure 4. Dextrin as a depressant was evaluated only at $\mathrm{pH}$ values of 3,5 , and 9 .

A baseline test, where no depressant was added to the flotation pulp, showed that the iron-containing mineral, haematite, has the highest natural hydrophobic tendency, (floatability) around $\mathrm{pH} 7$, where a low recovery of $\mathrm{Fe}_{2} \mathrm{O}_{3}$ to the silica rougher tails is noted. This tendency decreases at pH levels below and above $\mathrm{pH} 7$ where lower flotation recoveries are obtained, as seen in Figure 4. As also shown in this figure, the normalized iron grade in the silica rougher tails decreases below and above $\mathrm{pH} 7$. This is due to the change in surface charge to where $\mathrm{Fe}^{2+}$ ions predominate on the particle surfaces.

At pH 3, no significant change in either the iron grade or the iron recovery could be established by adding $400 \mathrm{~g} / \mathrm{t}$ depressant. At pH 5, however, an increase in the iron recovery, from $32.0 \%$ to $41.0 \%$, could be attained with starch addition and to $51.0 \%$ Fe recovery with Dextrin addition. The decrease in iron grade at $\mathrm{pH} 5$, from normalized $23.1 \% \mathrm{Fe}$

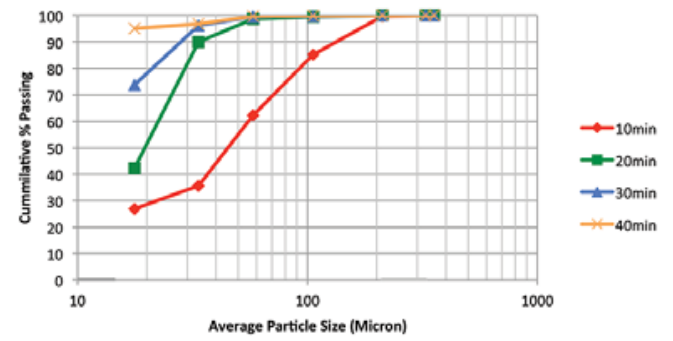

Figure 3-Grinding curve analysis for the African iron ore feed

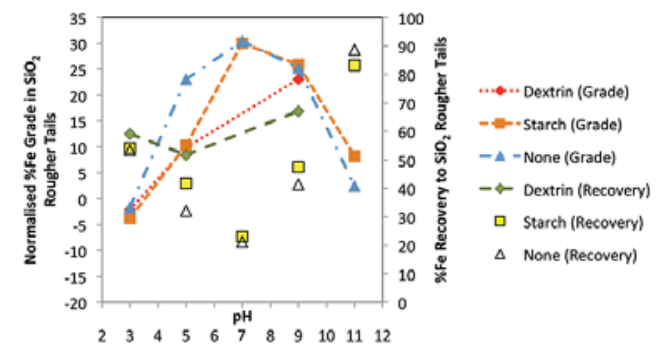

Figure 4-Normalized \%Fe grade and recovery to silica rougher tails as a function of flotation $\mathrm{pH}$ for starch, dextrin, and no depressant 


\section{Optimization of flotation pH for the flotation of a low grade haematite ore}

(where no depressant was used) to between 9.9\% and 10.3\% Fe (for either dextrin or corn starch) can be attributed to the non-selectivity of the depressants at this $\mathrm{pH}$, thus quartz minerals are also depressed. At pH 9, a slight increase in the iron grade is noticed with the use of starch as a depressant, where a normalized iron grade of $25.9 \%$ Fe was obtained. Dextrin at this pH resulted in an iron recovery of $67.0 \%$ at a normalized $23.1 \%$ Fe grade.

Additional tests at $\mathrm{pH} 7$ showed that the use of starch and no depressant produces similar results. Here the increase to a normalized $30.1 \%$ Fe grade (for starch) and $30.4 \% \mathrm{Fe}$ (for no depressant) is offset by iron recoveries of $23.2 \%$ and $21.2 \%$. At pH 11, where $\mathrm{Fe}^{3+}$ ions predominate on the particle surface, a high iron recovery of more than $80 \%$ could be attained only at a normalized iron grade of $8.2 \% \mathrm{Fe}$ (for starch) and 2.4\% Fe (for no depressant).

Figure 4 corroborates the theory that the adsorption of the depressant on an oxide mineral surface is driven by the surface charge. In terms of the normalized iron grade in the silica rougher tails, it also shows very little difference between the types of depressant in slightly alkaline conditions.

The addition of a sodium silicate dispersant was tested to improve the selectivity of the reagent suite in conjunction with starch as a depressant. Figure 5 compares a baseline test, where no dispersant used, to the use of $80 \mathrm{~g} / \mathrm{t}$ and 100 $\mathrm{g} / \mathrm{t}$ of two dispersant types. The figure also shows the iron recovery obtained using each dispersant type and dosage corresponding to the best normalized iron grade.

Figure 5 shows that when using $80 \mathrm{~g} / \mathrm{t}$ FloatSil 1 as a dispersant, the normalized iron grade was increased to $28.4 \%$ Fe at pH 9 and 20.5\% Fe at pH 5. Using this dispersant resulted in an iron recovery of $63.5 \%$ at pH 7 and $58.2 \%$ at $\mathrm{pH}$ 9. The use of FloatSil2 at $\mathrm{pH} 5$ resulted in no improvement in terms of the normalized iron grade, compared to a test where no dispersant was used. Changing the dispersant type to FloatSil2 or increasing the FoatSil1 dispersant dosage to $100 \mathrm{~g} / \mathrm{t}$ did not result in any significant improvement in the iron grade at $\mathrm{pH} 9$.

\section{Selectivity from pulp basicity}

The influence of the pulp pH in the laboratory flotation test is more significant than the influence of the starch depressant dosage over a broad pH range, as shown in Figure 6 . The iron grade in the silica rougher tails seems to be influenced only marginally by an increase of depressant dosage from $100 \mathrm{~g} / \mathrm{t}$ up to $800 \mathrm{~g} / \mathrm{t}$ (especially at pH 9).

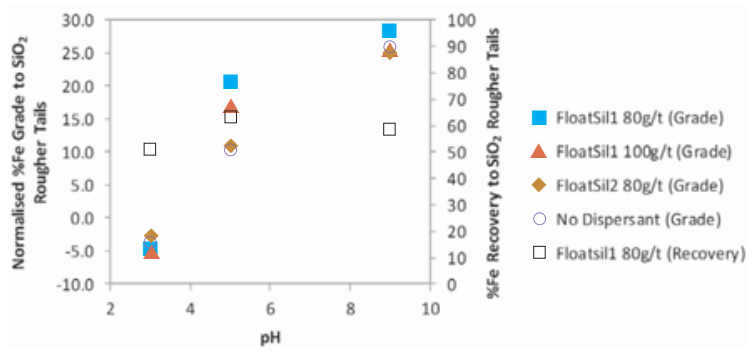

Figure 5-Normalized \%Fe grade and recovery as a function of flotation pH for FloatSil1 and FloatSil2 dispersants, with a no dispersant baseline
Figure 6 shows that it would be beneficial during reverse flotation to keep the flotation $\mathrm{pH}$ range between neutral and slightly alkaline, when the higher normalized iron grade values at $\mathrm{pH} 7$ and $\mathrm{pH} 9$ are considered.

This test work is to be used for further optimization studies, thus it is critical to consider the recovery of iron minerals to the product as well. Turrer and Peres (2010) noted good flotation performance in the region of more than $40 \%$ Fe recovery.

Figure 7 shows that although the normalized iron grade in the silica rougher tails could be increased to above $29 \% \mathrm{Fe}$ at $\mathrm{pH} 7$, the higher iron recovery at $\mathrm{pH} 9$, (more than 35\%), irrespective of the depressant dosage, makes pH 9 a more suitable pH level for reverse flotation of this African iron ore. This again confirms the strong dependence of the flotation result on the surface charge of the floated mineral (quartz), as a result of the specific pulp pH environment.

\section{Conclusions}

The test work presented in this article forms part of a more complete and in-depth study and shows that for the reverse flotation of iron ore, the flotation $\mathrm{pH}$ is more significant than the depressant types and dosage. It also underlines the importance of the surface chemical effects and indicates that flotation in a slightly alkaline pulp environment, where better iron recoveries are attainable, serves as good baseline conditions for further flotation optimization.

\section{Acknowledgements}

The authors thank Anglo American for financial support of this project, Anglo American Technical Solutions for the preparation of the ore, and William le Roux, the milling assistant, for flotation work at the University of Pretoria.

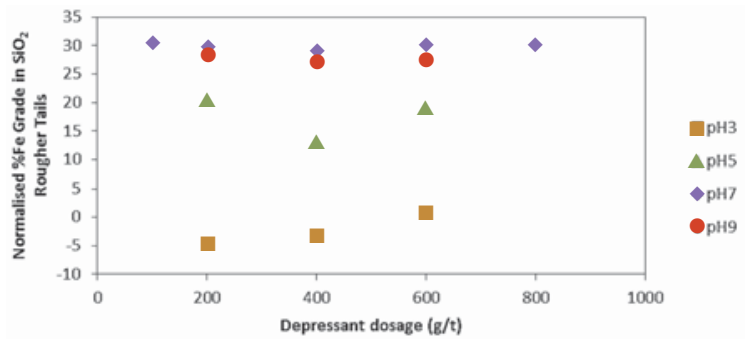

Figure 6-Normalized \%Fe grade in silica rougher tails as a function of depressant dosage

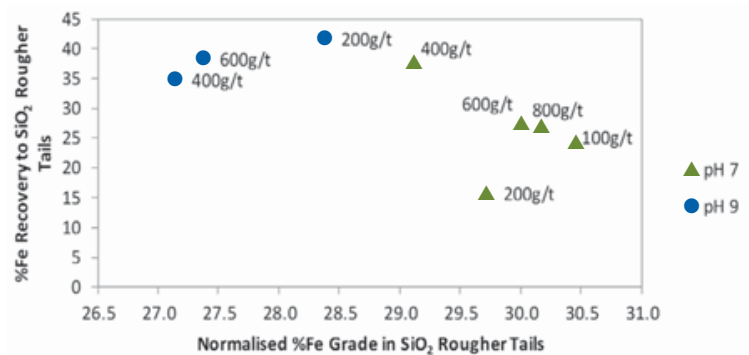

Figure 7-Normalized \%Fe grade-recovery curve for flotation at $\mathrm{pH} 7$ and $\mathrm{pH} 9$, indicating various depressant dosages 


\section{Optimization of flotation pH for the flotation of a low grade haematite ore}

\section{References}

Alvarez-Silva, M., Uribe-Salas, A., Mirnezami, M., and Finch, J.A. 2010. The point of zero charge of phyllosilicate minerals using the Mular-Roberts titration technique. Minerals Engineering, vol. 23. pp. 383-389.

Araujo, A.C., Viana, P.R.M., and Peres, A.E.C. 2005. Reagents in iron ores flotation. Minerals Engineering, vol. 18. pp. 219-224.

Astrup, J., HAMmerbeck, E.C.I., and van Den Berg, H. 1998. Iron. The Mineral Resources of South Africa. Wilson, M.G.C. and Anhaeusser, C.R. (eds.). Handbook 16, Council for Geoscience, Pretoria. pp. 402-416.

Fuerstenau, D.W. and Pradip. 2005. Zeta potentials in the flotation of oxide and silicate minerals. Advances in Colloid and Interface Science, vol. 114-115. pp. 9-26.

SIRKECI, A.A. 2000. Electrokinetic properties of pyrite, arsenopyrite and quartz in the absence and presence of cationic collectors and their flotation behaviour. Minerals Engineering, vol. 13, no. 10/11. pp. 1037-1048.

TurRer, H.D.G. and Peres, A.E.C. 2010. Investigation on alternative depressants for iron ore flotation. Minerals Engineering, vol. 23. pp. 1066-106.

VieIRA, A.M. and Peres, A.E.C. 2007. The effect of amine type, pH, and size range in the flotation of quartz. Minerals Engineering, vol. 20 pp. 1008-1013. 